\title{
When and Why Are Campaigns' Persuasive Effects Small? Evidence from the 2020 US Presidential Election*
}

\author{
David E. Broockman ${ }^{\dagger} \quad$ Joshua L. Kalla ${ }^{\ddagger}$
}

September 7, 2021

\begin{abstract}
Why do political campaigns so often fail to persuade voters, and what does this say about voter decision-making? Some interpret the difficulty of persuading voters as evidence of "partisan intoxication"-i.e., that voters remain loyal to their parties even when confronted with new information. However, an informational (Bayesian) mechanism may also contribute. We test empirical implications of these possibilities in data from four survey experiments (total $n=113,742$ ) conducted during the 2020 Presidential election that exposed individuals to 291 unique messages. Our results provide new evidence supporting the Bayesian interpretation: we show that voters are more persuadable with information about candidates they know less about; that this persuasion includes both large changes in beliefs and meaningful changes in vote choice, including partisan defection; and that messages with more informational content are more persuasive. These results support a role for Bayesian reasoning, and not only partisan loyalty, in the small size of campaign effects.
\end{abstract}

${ }^{*}$ We thank Gabe Lenz, Jas Sekhon, Alex Coppock, Seth Hill, Andrew Little, Lynn Vavreck, John Bullock, and Anthony Fowler for helpful feedback. All remaining errors are our own. This research was approved by the Yale University and University of California, Berkeley IRBs. We thank the Silicon Valley Community Foundation and the Tides Foundation for support.

${ }^{\dagger}$ Associate Professor, Travers Department of Political Science, University of California, Berkeley. dbroockmaneberkeley.edu, https://polisci.berkeley.edu/people/person/david-brooc kman

Assistant Professor, Department of Political Science and Department of Statistics and Data Science, Yale University. josh.kalla@yale.edu, https://joshuakalla.com 
“...facts don't change our minds."

- Elizabeth Kolbert, The New Yorker

Consistent with a longstanding tradition in scholarship on the "minimal effects" of campaigns (Brady, Johnston and Sides 2006), field experiments generally document near-zero marginal effects of most campaign advertising on vote choice in US Presidential general elections. ${ }^{1}$ However, campaign advertising appears to have larger effects when it is conducted early in an election season (although these effects typically decay) or in nonpartisan elections, such as primaries or ballot measures (Kalla and Broockman 2018).

What accounts for these broad, stylized facts about voter persuasion in campaigns—and what do they say about the nature of voter decision-making? One could interpret these broad patterns as consistent with two, quite distinct perspectives.

First, these patterns could be interpreted as consistent with "partisan intoxication" (e.g., Campbell et al. 1960; Achen and Bartels 2016, but see Fowler et al. (2020)): that voters in partisan elections resist information contrary to their partisan loyalties and are not motivated to form accurate judgments; i.e., that "facts don't change our minds." Such "intoxication" would not come into play in nonpartisan elections; but, as the salience of partisan identities has been found to increase close to elections (Michelitch and Utych 2018), could greatly diminish voters' openness to persuasion as a partisan election gets closer. For example, Kalla and Broockman (2018) speculate that high levels of affective polarization might be responsible for the miniscule effects of campaign persuasion they find (p. 148).

A second interpretation offers a radically different portrait of voters: that voters are behaving as Bayesian reasoners, who put less weight on new information when their prior beliefs are stronger (e.g., Bullock 2009; Hill 2017), such as later in a campaign season or when a candidate has a party label that provides a strong signal about them. As DellaVigna and Gentzkow (2010, p. 654) note, in models of Bayesian updating, "the weaker receivers' priors are, the more their beliefs

\footnotetext{
${ }^{1}$ Dunning et al. (2019) find similar results in meta-analyses of informational campaigns in developing countries.
} 
are affected by a given piece of new information," all else equal. Partisanship is a strong signal about candidates' likely policy positions and priorities. This should provide voters strong prior beliefs about candidates in partisan elections and therefore reduce the marginal effect of additional information on vote choice in partisan elections. Moreover, as voters learn more about candidates over the course of an election campaign (Gelman and King 1993; Le Pennec and Pons 2019), they should form increasingly strong priors about each candidate, further diminishing the marginal effect of any additional information they receive on vote choice, even if this additional information is novel 2

Unfortunately, existing research on campaign effects is unable to differentiate between these two interpretations: as Table 1 summarizes, both a "partisan intoxication" interpretation (for review and critique, see Fowler et al. 2020) and an informational or Bayesian interpretation can be reconciled with the broad patterns found in existing research. For example, according to the "partisan intoxication" view, "facts don't change our minds" due to our pre-existing partisan loyalty; but, under the informational or Bayesian view, voters often do not change their minds in response to campaign messages precisely because they are acting like more sophisticated reasoners.

However, it is vital to distinguish between these two interpretations, as they suggest very different understandings not only of voter responses to campaign communication, but of voter reasoning itself. Does how we observe voters react to campaign communication support a view of voters as simply blind partisans, or are these patterns actually consistent with voters attempting to assimilate new information into their judgments in a manner resembling Bayesian reasoning?

\footnotetext{
${ }^{2}$ Similarly, as Arias et al. (2018 p. 2) note, "if voters already believe that their incumbent party is malfeasant, even revelations of relatively severe malfeasance can fail to decrease incumbent support if voters favorably or neutrally update their posterior beliefs based on information that is not more serious than expected" (see also Humphreys and Weinstein 2012, Banerjee et al. 2011; Ferraz and Finan 2008, but see Dunning et al. (2019)). See related arguments regarding the lower effect of information for individuals who already have more considerations in their "consideration pool" (Zaller 1992), in debates about the comparative effects of spending by challengers and incumbents (Jacobson 1990: Green and Krasno 1990), and evidence on the high marginal effects of increasing challenger name recognition (Panagopoulos and Green 2008).
} 
Table 1: Observational Equivalence of the "Partisan Intoxication" and Information Interpretations on Campaign Advertising Effects in Partisan Elections

\begin{tabular}{l|l|l|}
\hline Pattern & $\begin{array}{l}\text { "Partisan Intoxication" } \\
\text { Interpretation }\end{array}$ & $\begin{array}{l}\text { Informational or } \\
\text { Interpretation }\end{array}$ \\
\hline $\begin{array}{l}\text { Campaign effects are } \\
\text { small because... }\end{array}$ & $\begin{array}{l}\text { it is difficult to persuade partisan } \\
\text { voters to vote for an outpartisan } \\
\text { candidate }\end{array}$ & $\begin{array}{l}\text { voters possess prior information } \\
\text { about candidates, including } \\
\text { inferences they make from party } \\
\text { labels }\end{array}$ \\
$\begin{array}{l}\text { Campaign effects } \\
\text { are smaller closer to } \\
\text { election day because... }\end{array}$ & $\begin{array}{l}\text { the salience of partisan identities } \\
\text { increase closer to election day }\end{array}$ & $\begin{array}{l}\text { voters have learned more about } \\
\text { the candidates, so the marginal } \\
\text { effect of additional information is } \\
\text { smaller }\end{array}$ \\
$\begin{array}{l}\text { Campaign effects are } \\
\text { smaller in partisan } \\
\text { than in nonpartisan } \\
\text { elections because... }\end{array}$ & to their partisan identities & $\begin{array}{l}\text { voters resist information contrary } \\
\text { candidate party is informative } \\
\text { about candidates, giving voters } \\
\text { stronger priors about candidates } \\
\text { in partisan elections; with } \\
\text { stronger priors, the marginal } \\
\text { effect of additional information is } \\
\text { smaller }\end{array}$ \\
\hline
\end{tabular}

To shed light on these questions, we present results from several surveys we conducted during the 2020 US Presidential election campaign (specifically four surveys conducted from January-May, 2020 which contained $n=113,742$ independently randomized observations across $n=69,270$ unique survey responses). We placed several experiments on these surveys which allow us to isolate a number of distinct empirical implications of the "partisan intoxication" and Bayesian interpretations of variation in campaign effects. An important advantage of our surveys, and a major difference between it and previous experimental research ${ }^{3}$ is that we are able to conduct our comparisons within the same electoral context. This means that we are able to

\footnotetext{
${ }^{3} \mathrm{Few}$ existing experiments test the effectiveness of appeals on behalf of two opposing candidates within the same election, one of which voters have more prior information about than the other; our experiments do so. Field experiments on attempts to change vote choice are typically conducted in partnership with and implemented by campaigns advocating for one party or candidate over others, so such experiments are rare. Wantchekon (2003) and Panagopoulos and Green (2008) are the only field experiments we are aware of that satisfy this criterion. Panagopoulos and Green (2008) examine the effect of nonpartisan ads that provide information on the names of the candidates, finding that increasing challenger name recognition increases the challenger's vote share.
} 
naturally hold constant features of the context, testing alternative implications of the two interpretations of campaign effects we are testing without concern that other features of the election context vary.

In our experiments, we exposed participants in a randomized treatment group to (usually) two statements about one of either Biden or Trump and which were either positive or negative. Across our experiments, there are participants in a control group, an anti-Trump statement group, a proTrump statement group, an anti-Biden statement group, and a pro-Biden statement group. To improve the ecological validity of the study and help demonstrate the robustness of the findings across multiple realizations of each treatment, we composed 291 distinct statements that we use across the studies. For the anti-Trump and anti-Biden statements, we also intentionally made some of these statements "vague," providing little information, and some "specific," providing specific factual information.

We use this data to test a number of competing predictions of the "partisan intoxication" and informational interpretations of when and why campaigns persuade. Our findings are broadly consistent with the predictions of an informational or Bayesian interpretation of variation in campaign effects, and often contradict what an exclusively "partisan intoxication" interpretation would predict.

First, we would expect voters to have had strong priors about Donald Trump because he had been President for nearly four years at the time of the study, and had received consistently high levels of media coverage. On the other hand, we would expect Americans to have had weaker priors about Joe Biden and to have known much less about his background, positions, etc. Consistent with these expectations, on a favorability question we asked in one of our surveys, twice as many Americans selected the scale midpoint for Biden than Trump (see Figure A1). Likewise, Table 2 shows data from a national survey from YouGov in late March 2020, finding that over three times as many people said they had heard "a lot" about Donald Trump during the last week than as about 
Biden 4

Table 2: "How much have you read, heard, or seen anything about the following people during the last week?"

\begin{tabular}{c|cccc} 
& A lot & Some & A little & None \\
\hline Donald Trump & $61 \%$ & $21 \%$ & $10 \%$ & $8 \%$ \\
Joe Biden & $17 \%$ & $31 \%$ & $28 \%$ & $24 \%$
\end{tabular}

Notes: Yahoo! News/YouGov survey, March 25-26, MOE $\pm 3.1 \%$.

In this context, the informational interpretation would predict larger effects on vote choice when voters are provided information about the candidate about whom they have weaker prior beliefs (Biden) than about the candidate about whom they have strong prior beliefs (Trump). A strictly "partisan intoxication" interpretation would predict equally limited effects regardless of which candidate the appeals considered, and no persuasive effect from appeals that run contrary to one's partisan viewpoint.

We find that both positive and negative messages about Biden have significantly larger effects on stated vote choice than either positive or negative messages about Trump. This is consistent with voters having stronger priors about Trump and so additional information about Trump having a smaller effect on vote choice than information about Biden. Further results suggest that the very small effects on vote choice we do find for information about Trump do not conceal important heterogeneity; the data are most consistent with none of the 161 anti-Trump messages we tested having effects as large as the anti- or pro-Biden messages.$^{5}$ In contrast to prior findings that persuasion is difficult in presidential elections, our results show that voters can be persuaded in either direction in a presidential election when given information about a candidate about

\footnotetext{
${ }^{4}$ See https://today.yougov.com/topics/politics/articles-reports/2020/03/30/ya hoo-newsyougov-most-americans-heard-lot-about-pr.

${ }^{5}$ In particular, we take advantage of the fact that we tested over 200 distinct statements about Trump to investigate whether the very small effects we do find represent genuine persuasion. Using a meta-analytic procedure, we find that the data is most consistent with every single negative statement we showed participants having an identical, very small effect, with there being no dispersion in the effects of dramatically different treatments. We confirm this by showing that re-testing the statements estimated to have the largest effects in a first round of data collection completely regress to the mean in a subsequent round of data collection.
} 
whom they have weaker prior beliefs_-but that persuading voters in that same election by trying to change their views about a candidate about whom they have stronger prior beliefs is much more difficult.

Second, consistent with our finding that persuasive messages have small effects to the extent that voters have strong prior beliefs about the candidate the message concerns, we also find that respondents' favorability ratings of Biden change dramatically in response to information about Biden, but that changes in Trump favorability are significantly smaller. It is not that voters in partisan or even Presidential elections are impervious to information that changes their evaluations of candidates; rather, it is simply more difficult to change voters' evaluations of candidates they have strong prior beliefs about.

Third, inconsistent with the "partisan intoxication" account, we show that the persuasion we documented results from voters crossing party lines: Republicans are persuaded to vote for Biden after reading pro-Biden information. The effects we found on vote choice do not merely or even primarily reflect partisans "coming home" to support their party's candidate.

Fourth, we show that the informational content of persuasive messages voters receive also matters in a manner consistent with an informational or Bayesian interpretation: in particular, voters are more persuaded when exposed to campaign messages that contain richer informational content. In particular, for information about Joe Biden, where we do appear to find genuine persuasion from both positive and negative information, we further show that "specific" informational statements that provide factual information are more effective than "vague" statements that make vague assertions without providing any new, specific information. Although it is often offered as a truism that "facts don't change our minds," we found that it was especially messages with factual information that did so.

Fifth, we show that the information we gave respondents about Trump was often novel to them and changed their views of Trump's performance in the specific domain relevant to that information (e.g., his performance on environmental protection), even as they failed to 
meaningfully change global evaluations of Trump or intended vote choice. This suggests that the lack of meaningful effects from the information we showed respondents about Trump is unlikely to be due to voters simply rejecting all new information about Trump (or to deficiencies in the treatments we provided); rather, voters' overall priors about Trump were sufficiently strong that even changes in perceptions of Trump on particular dimensions are not sufficient to meaningful alter global evaluations of Trump, given the strength of respondents' priors.

These results are all consistent with an informational interpretation of variation in the magnitude of campaign persuasion across voters, messages, and candidates, and often difficult to explain only with "partisan intoxication." Our findings in no way demonstrate that partisanship never matters, but do suggest - even at a period of intense partisan polarization - that it is not the whole story.

In concluding, we discuss the implications of our findings, as well as their limitations. In particular, although our experiments have the disadvantage that they only occur in one particular election with only two particular candidates, they have the advantage that aspects of the election and its voters are naturally held constant, allowing us to compare effects of our treatments on the same dependent variable with the same meaning in the same context at the same time with real, rather than hypothetical candidates (McDonald 2019). The fact that we tested many realizations of our treatments also suggest that our results do not depend on any one specific set of messages, and our deliberate variations in message type also further reinforce our conclusions. Nevertheless, future research should replicate the set of key comparisons we have identified in future elections and in a field context.

\section{Data and Methods}

Our experiments were embedded in a series of four surveys conducted in early 2020 . Online Appendix $B$ describes the surveys, the pre-analysis plan we filed for the first survey, and how we 
sought to further validate our findings in subsequent surveys. The surveys span $n=69,270$ unique respondents. Because many of the survey responses are used in multiple experiments (e.g., because the same survey had two independently randomized experiments in succession), our analyses include $n=113,742$ independently randomized observations. We conducted these surveys using Lucid, which Coppock and McClellan (2019) find well-approximates national Census benchmarks and produces experimental results which well-approximate other national samples.

The surveys began by asking respondents for their informed consent and ensuring that they were paying attention. Only respondents who provided consent and passed two pre-treatment attention checks could proceed in the study. ${ }^{6}$ Next, we asked several pre-treatment measures that we expected to predict our dependent variables. As described more below and specified in our pre-analysis plan (see Appendix D), we condition on these measures in our analyses in order to increase the precision of our estimates, using the method in Bloniarz et al. (2016). These included pre-treatment self-reported ideology, questions from the right-wing authoritarianism and social dominance orientation scales, favorability towards Trump, the police, and Congress, 2016 Presidential vote choice, a US House generic ballot question, and three measures of economic perceptions. We also have access to pre-treatment measures of respondents' region, party identification, ethnicity, education, age, gender, and household income from the survey provider, Lucid.

\footnotetext{
${ }^{6}$ The first attention check asked: "For our research, careful attention to survey questions is critical! We thank you for your care." Respondents were shown "I understand" and "I do not understand" in a randomized order. If a respondent did not select "I understand", they were removed from the survey. Similarly, the second attention check asked: "People are very busy these days and many do not have time to follow what goes on in the government. We are testing whether people read questions. To show that you've read this much, answer both 'extremely interested' and "very interested." Respondents were shown "Extremely interested", "Very interested", "Moderately interested", "Slightly interested", and "Not interested at all". If a respondent did not select both "Extremely interested" and "Very interested" and nothing else, they were removed from the survey.
} 
Table 3: Overview of Survey Data and Treatments

\begin{tabular}{|c|c|c|c|}
\hline Survey & Dates & Anti-Trump & Anti-Democrats \\
\hline \multirow[b]{2}{*}{1} & \multirow[b]{2}{*}{$1 / 6-2 / 9$} & 36,236 respondents & 25,234 respondents; 5,011 for Biden \\
\hline & & 262 statements, specific and vague & $\begin{array}{l}52 \text { statements; } 11 \text { for Biden, } \\
\text { specific and vague }\end{array}$ \\
\hline \multirow[b]{2}{*}{2} & \multirow[b]{2}{*}{$2 / 9-2 / 24$} & 16,338 respondents & 14,905 respondents; 2,934 for Biden \\
\hline & & $\begin{array}{c}61 \text { statements, specific and vague, } \\
\text { selected as the most } \\
\text { persuasive from Survey } 1\end{array}$ & $\begin{array}{l}30 \text { statements; } 6 \text { for Biden, } \\
\text { specific and vague } \\
\text { selected as the most } \\
\text { persuasive from Survey } 1\end{array}$ \\
\hline \multirow{3}{*}{3} & \multirow{3}{*}{$3 / 25-4 / 1$} & 4,945 respondents & \\
\hline & & & \\
\hline & & 233 statements, specific and vague & \\
\hline \multirow[t]{2}{*}{ Survey } & Dates & Pro-Trump & Pro-Biden \\
\hline & & 6,434 respondents & 7,710 respondents \\
\hline \multirow[t]{2}{*}{4} & $4 / 12-5 / 27$ & & \\
\hline & & 8 statements, all specific & 10 statements, all specific \\
\hline
\end{tabular}

Note: Respondents are those individuals who answered the 2020 presidential vote choice outcome measure. Placebo respondents are included in the sample sizes reported above and are counted in both the Trump and Democrats/Biden columns.

\section{Experimental Manipulations}

We conducted experiments showing respondents anti-Trump statements, anti-Democratic candidate statements, pro-Trump statements, or pro-Democratic candidate statements (see Table 3 for an overview). The anti-Democratic candidate experiments were conducted before Joe Biden became the presumptive Democratic nominee, and so were conducted across the five leading contenders for the nomination at the time (Biden, Bloomberg, Buttigieg, Sanders, and Warren). We focus on the data for Joe Biden below, but also show that our results are consistent across the other candidates, 7

Before showing respondents these statements, we told them that we would show them a series

\footnotetext{
${ }^{7} \mathrm{We}$ separately report additional findings on the relationship between Democratic candidate ideology, voter support, and the effects of the negative statements in Broockman and Kalla (2020).
} 
of example media stories and were interested in their reactions. In the control group in each experiment, voters then saw prompts like the below, giving the context of the Presidential election. The below is an example of the media story we showed respondents in the anti-Democratic statements experiments when Joe Biden was the candidate:

The 2020 election for US President is getting started. Donald Trump and his supporters have been making many arguments about why Americans should not vote for the Democrats running for President.

One of the Democrats running for President is Joe Biden. Some of Trump's supporters have argued Joe Biden should not be President.

In treatment groups that were shown the statements, respondents were then shown:

Criticizing Joe Biden, some of Trump's supporters have said:

- Statement 1

- Statement 2

where we replaced "Statement 1" and "Statement 2" with the statements to which respondents were randomly assigned, as described below. All the vignettes attributed the statements to advocates for one side and did not present the statements as neutral factual statements.

After we showed respondents the example media story, we asked them to rate the story. We then showed all respondents another distractor story about the presidential election which contained no arguments for or against the candidates being studied.

After the distractor story, we then asked our main dependent variables of interest: 2020 vote choice, followed by a strength of support question for those who were decided and a leaner question for those who were not; favorabiltiy questions about Trump and (in the pro-statement studies) Biden; and a job approval question about Trump. Next, we asked respondents to rate their approval 
of Trump's performance on each of five topics, including, if in the vague or specific group, the topic to which they were randomly assigned to see statements about as part of the treatment.

In the cases when respondents were part of two experiments (e.g., the anti-Trump experiment then the anti-Democratic experiment), we always included filler material for other studies not about the 2020 election between the two experiments.

\section{Random Assignment}

We randomly assigned which statements respondents would see as follows.

\section{Anti-Trump and Anti-Democratic Experiments: "Specific" and "Vague" Statements}

For respondents in the anti-Trump and anti-Democratic experiments, we randomly assigned whether respondents in the treatment group were exposed to "specific" or "vague" statements criticizing the candidates.

We drew the vague statements from existing political communication in almost all instances, usually by opposing candidates. For example, one of the vague statements attacking Trump was taken from Elizabeth Warren, who said at a rally:

"Donald Trump is corruption in the flesh. He's sworn to serve the people of the United States, but he only serves himself and his partners in corruption. Corruption has taken over our government and we are running out of time. 8

We sometimes made minor edits to the statements for grammar and length.

An informational interpretation of campaign effects would predict that these statements would have little effect on support for Trump because they do not provide information - they are vague. At best, they emphasize aspects of Trump's performance in office that listeners are presumed to

\footnotetext{
${ }^{8}$ Transcript available at https://www.rev.com/blog/transcripts/elizabeth-warren-new-y ork-city-rally-transcript-september-16-2019-full-speech-transcript.
} 
already be familiar with (Leeper and Slothuus 2018; Coppock 2016). Consistent with the hypothesis in our pre-analysis plan regarding "the superiority of providing information to emphasis" and an informational interpretation of any persuasion we would see, we expected that statements that provide specific information would be more effective than those which merely emphasize what individuals are presumed to already know. An example of a specific statement on the same theme is the following:

"Donald Trump has spent 99 days at Mar-a-Lago, the Palm Beach resort he owns, since becoming president. It costs $\$ 200,000$ to join the private club. When Trump is there, club members often meet and lobby him. Many people have paid to join the club since Trump was elected; this means wealthy people and foreign governments pay money to Trump personally that allows them to gain access to him when he is there."

For Donald Trump, we composed 161 specific statements and 77 vague statements of this form. The vague statements were based on existing campaign rhetoric, as described above, but we composed all 161 original statements ourselves..$^{9}$ For the Democratic candidates, we composed 42 specific statements and 10 vague statements ( 2 vague statements per candidate).

Random assignment in the anti-Trump and anti-Democratic experiments took place as follows. We first randomly assigned respondents to the control, vague, or specific conditions. For the antiTrump experiment, we next randomly assigned respondents in the vague and specific conditions to a topic (e.g., "corruption"). All specific and vague statements were grouped into topics, with each topic having both specific and vague statements. Some topics had more specific statements

\footnotetext{
${ }^{9}$ To do so, we began by locating 77 vague attacks that Democratic politicians and left-leaning organizations had made against Donald Trump. Most of these statements were sourced from campaign rallies and Democratic presidential primary debates. We do not claim that these statements represent a random sample of all attacks on Trump or are representative of the attacks Democrats made during the 2020 general election; however, by collecting a very large number of statements, we increase the external validity of our experiment and can empirically assess whether our conclusions meaningfully vary by which stimuli we use. Next, we categorized these vague attacks into each of 28 topics (e.g., "climate change"; "corruption while in office"). We then researched Trump's record on each topic, finding and summarizing specific information in each of 161 original statements that we composed.
} 
associated with them than others; and topics were selected in proportion to the number of specific facts we had prepared per topic. This ensured that each specific fact was shown to a similar number of respondents and that respondents in the "specific" and "vague" groups were exposed to each topic with the same frequency. Finally, for both the anti-Trump and anti-Democratic experiments, two of the specific or vague statements were randomly selected to be shown, depending on the respondent's random assignment. In the anti-Trump experiment, these two statements were always within the topic selected. This random assignment to statements allows us to calculate statementlevel treatment effects 10

Table 4 shows examples of the statements in each of the experiments. Appendix Clists all the statements.

\section{Pro-Trump and Pro-Democratic Survey}

In the pro-Trump and pro-Democratic survey (Survey 4 in Table 3), we randomly assigned respondents to a control condition, the pro-Trump condition, or the pro-Democratic condition. We composed 8 pro-Trump statements and 10 pro-Biden statements. Respondents assigned to the pro-Trump or pro-Biden condition were randomly assigned to see 2 statements each from this bank of available statements. All of these statements were written as to be "specific."

Table 4 shows examples of the statements. Appendix Clists all the statements.

\section{Analysis}

Despite the large sample sizes of our surveys, we nevertheless sought to improve the precision of our treatment effect estimates using covariate adjustment given the prior literature's expectation of small treatment effects. Therefore, to analyze the effects of the statements on vote choice in the

\footnotetext{
${ }^{10}$ In the anti-Trump experiment, for the topics where only one or two statements were available, we randomly selected one statement to preserve our ability to estimate statement-specific effects. In the anti-Democratic experiment, there were only two vague statements per Democratic candidate, so respondents in the vague condition always saw both.
} 
Table 4: Example Statements Shown to Respondents

\begin{abstract}
Anti-Biden Joe Biden has long supported freezing government spending on Social Security, (Specific Medicare, Medicaid, and Veteran's Benefits. While he was a US Senator, he tried to Condition) cut these programs at least four times. Under Biden's proposal, Social Security and other benefits would not keep up with inflation, meaning these programs' value would decrease over time as prices rise, leaving seniors and veterans unable to maintain their current standard of living and or care.
\end{abstract}

Anti-Trump Scientists say that in order to avoid catastrophic effects of climate change, such (Specific as flooded coastal cities and farmland, extreme heat waves, wildfires, and extreme Condition) weather, the United States needs to reduce its carbon gas emissions. However, Donald Trump denies the existence of climate change and has opposed multiple proposals to reduce carbon emissions, such as tax rebates for solar panels or regulations on carbon dioxide as a pollutant.

Pro-Biden Joe Biden has a strong record of being able to work successfully with both Republicans and Democrats. As Vice President, he helped pass banking reforms, criminal justice reforms, and a weapons treaty with Russia, all of which passed with Republican votes. As President, he would have the skills and relationships to work with leaders of both parties, and move America past divisive partisan politics.

Pro-Trump As President, Donald Trump has successfully cut government red tape and unnecessary regulation. Since Trump took office, his administration has cut regulations nearly 400 times, saving taxpayers $\$ 50.9$ billion and making it easier and cheaper for businesses to hire workers and create jobs. Trump will continue cutting even more regulations.

Notes: See Appendix Cfor all statements.

2020 president election, as stated in our pre-analysis plan, we used an elastic net regression as a principled method for covariate selection and then estimated covariate-adjusted treatment effects, as recommended by Bloniarz et al. (2016) 11 When pooling across multiple surveys, we also

\footnotetext{
${ }^{11}$ To do this, we first formed a composite outcome variable which is the first dimension of a factor analysis combining vote choice in the 2020 presidential election, Trump favorability, and Trump approval. We then used a 20fold elastic net regression with this outcome and the pre-treatment covariates described above to select pre-treatment covariates highly prognostic of the outcome variable. This first regression does not include the treatment indicator. Then, following Belloni, Chernozhukov and Hansen (2014) and Bloniarz et al. (2016), we used the selected covariates to estimate the covariate-adjusted treatment effect by regressing the outcome variable on the treatment indicator and the pre-treatment covariates selected from the elastic net regression. For a similar application in political science, see Fang, Guess and Humphreys (2019).
} 
include survey fixed effects.

In the next section, we report the results from our survey experiments. Rather than report results from each survey experiment sequentially, we instead report the findings grouped together for substantive reasons.

\section{Results}

\section{Persuasive Effects are Larger For Statements about Biden than Trump}

An informational interpretation of campaign effects would predict that persuasive effects would be larger from messages about candidates whom voters have weaker instead of stronger prior beliefs. A "partisan intoxication" interpretation would predict similarly limited persuasive effects in a highly partisan election.

To test this, we first broadly examine the effects of the messages we tested, split by whether they concerned Biden (about whom we showed voters had weaker prior beliefs) or Trump (about whom voters had stronger prior beliefs). Figure 1 shows the average effect of the pro-Biden, anti-Biden, pro-Trump, and anti-Trump "specific" criticisms we showed respondents. We also pool the coefficients for the treatment effects of the statements about Biden and about Trump, shown in grey. The dependent variable is Trump vote margin, which is coded as $-1,0$, or 1 for respondents who said they would vote for Biden, neither, or Trump, respectively. We reverse the sign of the coefficients from the anti-Trump and pro-Biden criticisms so that all coefficients are coded so as to be in their expected directions, which all are. These effects are estimated with pretreatment covariates to improve precision using the pre-registered method described above. The full regressions are reported in Table A1.

As can be seen, the average effect of statements about Biden is much larger than the average effect of statements about Trump. The precision-weighted average effect of the Biden statements 
Figure 1: Effect on Vote Margin of Pro-Biden, Anti-Biden, Pro-Trump, and Anti-Trump Information

Effect on Trump Vote Margin (-1/0/1)

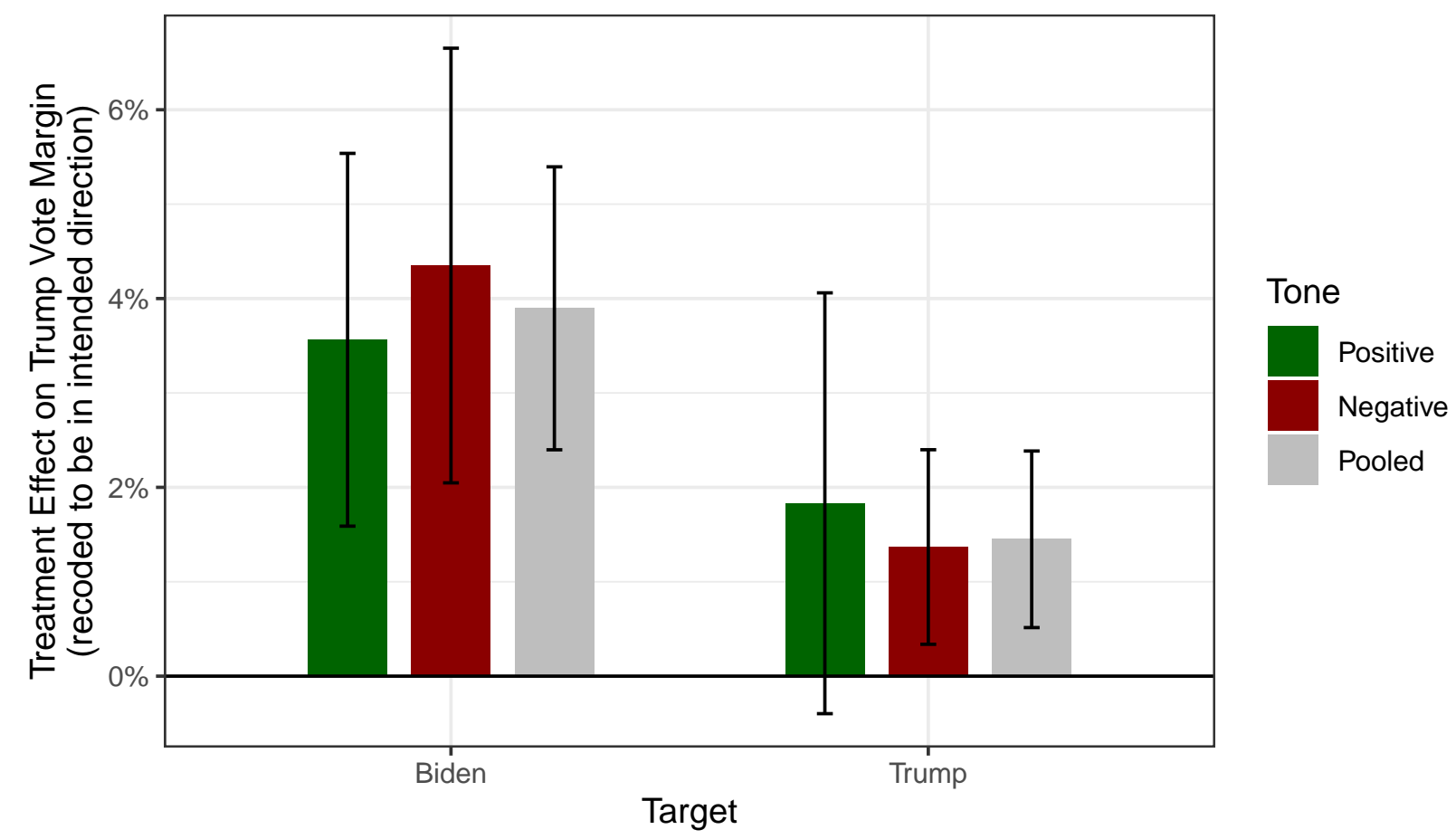

Notes: This Figure shows the average effects of showing respondents specific pro-Biden, antiBiden, pro-Trump, and anti-Trump statements on Trump vote share, coded as -1/0/1. The estimates are from multivariate regressions reported in Table A1] Results separated by survey are reported in Table A2. 95\% confidence intervals surround point estimates.

is 3.90 percentage points on vote margin ( $\mathrm{SE}=0.76$ ), as compared with 1.44 percentage points for Trump ( $\mathrm{SE}=0.48$ ). The difference in these estimates of 2.45 percentage points is significantly different from zero $(\mathrm{SE}=0.90, t=2.71, p=0.0066$ ). This result is consistent with an informational interpretation of why campaign effects are often small: people do not uniformly resist persuasion about partisan elections, but they are more difficult to persuade with information that seeks to change strong priors (such as about Trump) than with information that seeks to change weaker priors (such as about Biden). (We also show in Table A1 that the results are similar for the other Democratic candidates we conducted experiments for in the period before Biden had presumptively attained the Democratic nomination, if not larger.) 


\section{No Evidence Some Anti-Trump Messages Perform Better}

One possible alternative explanation for the findings in Figure 1 is that there is meaningful heterogeneity among the effects of anti-Trump messages: might it be that some of the anti-Trump messages are as or even more effective than the pro- or anti-Biden messages? We can exploit the unusually large number of anti-Trump messages we tested (161) to test this alternative explanation. Using both a variance decomposition and an out-of-sample replication, we find no evidence that there is meaningful heterogeneity in the effects of the anti-Trump statements; the data suggest that the anti-Trump statements all had similarly (very) small treatment effects.

Our first approach to demonstrating the (lack of) heterogenity in the effects of the anti-Trump messages is a variance decomposition exercise 12 In particular, we first compare the observed standard deviation of treatment effect estimates of the anti-Trump statements to the standard deviations that would be expected were all the treatments in fact equally effective (for a related test, see Dimmery, Bakshy and Sekhon 2019). To do so, we first ran a regression in the data from the anti-Trump experiment in Survey 1 (see Table 3 ) of the trichotomized (-1/0/1) vote choice question on indicators for the presence of every specific anti-Trump statement. We then computed the variance of these treatment effect estimates. Finally, we conducted a permutation test in which we re-randomized the data in the treatment group using the same randomization procedure as used to randomly assign the actual observations, assuming the sharp null that every statement had the same effect ${ }^{13}$ Since $\operatorname{Var}(X)+\operatorname{Var}(Y)=\operatorname{Var}(X+Y)$ for independent random variables, the variance of the observed effects in the experiment is the sum of the variance due to sampling error (randomization) and the variance of the true treatment effects. We see that the observed variance of treatment effect estimates in the data is essentially identical to the magnitude we would expect

\footnotetext{
${ }^{12}$ We had originally planned to conduct analyses predicting which factors predicted the persuasiveness of the statements (e.g., policy content vs. character content), but the procedure we used identified that there was likely no variation in persuasiveness across the statements except for that produced by sampling variability, leading us to abandon this planned analyses and present this analysis instead.

${ }^{13}$ We hold the control group fixed in these simulations. We use this procedure instead of a standard fixed effects meta-analysis both to improve interpretability and because the treatments are not independent, which randomization inference naturally accounts for.
} 
from sampling error alone, suggesting no remaining variation is due to variation in the true treatment effects (see Figure A2) ${ }^{14}$ This is what we would observe were all the treatments to have equal effect. In other words, our best estimate for the variance of the true treatment effects is zero.

Second, we used Survey 2 to conduct a true out-of-sample test for the presence of some antiTrump statements with larger treatment effects. After the conclusion of Survey 1, we selected the 23 anti-Trump statements with the largest (most negative) estimates on the Trump vote margin metric and the 23 anti-Trump statements with the largest (most negative) estimates on the first dimension of a factor analysis of Trump vote margin, Trump approval, and Trump favorability, for a total of 37 anti-Trump statements. We then re-tested the effect of these statements in the second round. Figure 2 shows the relationship between the effects of these statements in Survey 1 and Survey 2. The estimated effects for the statements with strongly negative estimates in Survey 1 regressed fully to the mean treatment effect in Survey 2, and there is essentially no correlation between the estimated treatment effects of each statement in Survey 1 and Survey $2(r=0.0032)$. This is consistent with all of the variation across each statement's effect being a result of sampling variability, and essentially none due to differences in their true treatment effects.

In summary, the (very) small average effects we estimated of the anti-Trump statements do not appear to conceal a subset of statements with larger effects; our best guess is that all the statements had similarly very small effects.

\section{Biden Favorability is Easier to Change than Trump Favorability}

Survey 4 included post-treatment measures of favorability towards Biden and Trump on a 7-point scale. Under the informational interpretation of variation in persuasion effects, views towards Biden should be more malleable than views towards Trump because people have more

\footnotetext{
${ }^{14}$ The average standard deviation of the observed estimates was 0.02220 . The average standard deviation of the estimates under the null was 0.02207 . $46 \%$ of permutations had standard deviations larger than observed standard deviation, so the p-value on the test of equal variances is 0.46 . Inverting the test, the top of the $95 \%$ confidence interval is a standard deviation of 0.02476 . This is sufficient to rule out scenarios wherein the true effects of the statements have a standard deviation of 0.0110 .
} 
Figure 2: Out of Sample Replication: Scatterplot of the Most Persuasive Anti-Trump Statements from Survey 1, Treatment Effects in Survey 1 and Survey 2



information (i.e., stronger prior beliefs) about Trump than about Biden. However, under a "partisan intoxication" interpretation, there is no particular reason to expect people to be more willing to change their mind about one candidate than the other; if anything, they should resist information about both.

To test these diverging predictions, Table 5 shows results from Survey 4, in which we showed respondents either pro-Trump or pro-Biden specific statements. Column 1 shows that pro-Trump specific statements had no discernible impact on favorability towards Trump. However, Column 2 shows that pro-Biden statements had meaningful and statistically significant effects on improving Biden's favorability. This is consistent with respondents having weaker prior beliefs about Biden they are therefore more willing to change in light of additional information about him.

\section{Republicans are Persuaded by Pro-Biden Information}

Which respondents do the pro-Biden statements persuade? If this persuasion were driven exclusively by Democrats, it could be interpreted as consistent with the "intoxicated partisans" 
Table 5: Effects on Biden and Trump Favorability from Survey 4

\begin{tabular}{lcc}
\hline & $(1)$ & $(2)$ \\
& Trump favorability & Biden favorability \\
\hline Pro-Trump & $\mathbf{0 . 0 2 5}$ & 0.003 \\
Specific Statements & $\mathbf{( 0 . 0 2 0 )}$ & $(0.038)$ \\
Pro-Biden & -0.023 & $\mathbf{0 . 1 9 9})^{* * *}$ \\
Specific Statements & $(0.018)$ & $\mathbf{( 0 . 0 3 3 )}$ \\
\hline Uses Covariates? & $\checkmark$ & $\checkmark$ \\
St. Dev. of DV & 2.43 & 2.09 \\
$N$ & 10,286 & 10,286 \\
$R^{2}$ & 0.897 & 0.513 \\
\hline
\end{tabular}

Standard errors in parentheses

${ }^{*} p<0.10,{ }^{* *} p<0.05,{ }^{* * *} p<0.01$

account, reflecting the hypothesis that campaigns reinforce voters' predispositions and cause partisans to "come home" (for review, see Henderson 2015). However, in Table 6, we show that there are clear effects of the pro-Biden treatments among Republicans: the pro-Biden treatment causes Republican voters to cross party lines and say they would vote for Biden instead of Trump. This is inconsistent with the notion that information merely pushes partisans into their corners (see also Coppock, Hill and Vavreck|2020).

Table A3 shows similar results for the anti-Trump statements: the effects, although very small, appear to be driven largely by Republican respondents.

\section{Specific Statements are More Persuasive than Vague Statements}

As mentioned previously, Surveys 1, 2, and 3 also randomized small proportions of participants to see "vague" attacks on Trump or the Democratic candidates instead of specific factual criticisms ${ }^{15}$ These vague attacks contained minimal information, and instead simply accused the candidates of poor performance, judgment, etc. without providing specifics (all statements are in Appendix C). In our pre-analysis plan for Survey 1, we noted that we tested the effect of these "vague" statements

\footnotetext{
${ }^{15} \mathrm{We}$ did not include any vague statements in the pro-Trump and pro-Biden tests in Survey 4.
} 
Table 6: Regression Results Showing the Effect of Positive Statements on Trump Vote Margin (-1/0/1) by Respondents' Baseline Partisanship

\begin{tabular}{lccc}
\hline & Democrats & Independents & Republicans \\
\hline Pro-Trump & 0.024 & 0.013 & 0.011 \\
Specific Statements & $(0.016)$ & $(0.035)$ & $(0.017)$ \\
Pro-Biden & -0.018 & $-0.072^{* *}$ & $-0.039^{* *}$ \\
Specific Statements & $(0.014)$ & $(0.032)$ & $(0.015)$ \\
\hline Uses Covariates? & $\checkmark$ & $\checkmark$ & $\checkmark$ \\
$N$ & 4,653 & 1,615 & 4,014 \\
$R^{2}$ & 0.44 & 0.49 & 0.53 \\
\hline Standard errors in parentheses & & \\
${ }^{*} p<0.10,{ }^{* *} p<0.05,{ }^{* * *} p<0.01$ & &
\end{tabular}

Note: Partisan leaners are coded as partisans. Data is from Survey 4.

in order to test "the superiority of providing information to emphasis" alone (see also Leeper and Slothuus 2018).

If the characterization of voters as forming steadily stronger beliefs about candidates based on information holds water, one would expect statements that contain more information to be more persuasive than vague statements. Table 7 shows that this is the case. The " $p$-value: Specific $=$ Vague" row shows the $p$-value on the test that the coefficients on the treatment effects for the specific and vague statements conditions are equal. For the anti-Trump statements, we see no difference, consistent with our earlier finding for specific statements that it is likely none of the statements had genuine effects. However, for the statements criticizing all the Democratic candidates (column 2), and Joe Biden specifically (column 3), we see much larger increases in Trump vote margin in response to specific attacks on Democratic candidates than vague attacks on them ${ }^{16}$ Rather than demonstrating that "facts don't change our minds," our results are most

\footnotetext{
${ }^{16}$ Survey 3 also contained a "both" condition in which we showed respondents one vague statement and one specific statement on the same topic to test the possibility that they are complements; intuitively, the possibility that persuasion requires both specific information and an overall frame emphasizing how people should be interpreting that information. However, we found no support for this alternative.
} 
consistent with factual information being much more effective in changing minds.

Table 7: Specific Statements are More Persuasive than Vague Statements

\begin{tabular}{|c|c|c|c|}
\hline & \multicolumn{3}{|c|}{ Trump Vote Margin (-1/0/1) } \\
\hline & (1) & $(2)$ & (3) \\
\hline Anti-Trump Specific Statements & $\begin{array}{c}-0.013^{* * *} \\
(0.005)\end{array}$ & & \\
\hline Anti-Trump Vague Statements & $\begin{array}{l}-0.013^{*} \\
(0.007)\end{array}$ & & \\
\hline Anti-Democratic Specific Statements & & $\begin{array}{c}0.064^{* * *} \\
(0.005)\end{array}$ & $\begin{array}{c}0.043^{* * *} \\
(0.012)\end{array}$ \\
\hline Anti-Democratic Vague Statements & & $\begin{array}{c}0.035^{* * *} \\
(0.007)\end{array}$ & $\begin{array}{c}0.019 \\
(0.016)\end{array}$ \\
\hline Uses Covariates? & $\checkmark$ & $\checkmark$ & $\checkmark$ \\
\hline Surveys / Subset & $1,2,3$ & 1, 2 (All Dem. Candidates) & 1, 2 (Biden Only) \\
\hline$p$-value: Specific $=$ Vague & 0.997 & 0.000 & 0.119 \\
\hline$N$ & 55,764 & 40,151 & 7,947 \\
\hline$R^{2}$ & 0.817 & 0.754 & 0.765 \\
\hline
\end{tabular}

Standard errors in parentheses

${ }^{*} p<0.10,{ }^{* *} p<0.05,{ }^{* * *} p<0.01$

\section{Anti-Trump Statements Did Change Views About Trump's Domain-Specific Performance, But Not Vote Choice}

A final alternative explanation for our findings regarding the relatively limited effects of anti-Trump statements is that voters simply rejected all new information about Trump due to their partisan allegiances: perhaps these allegiances particularly bind when it comes to information about an incumbent President. We cast doubt on this alternative explanation by showing that the anti-Trump statements were able to meaningfully alter respondents' views about Trump's performance in relevant domains.

In particular, in Survey 1 we asked participant to rate Trump's job approval in the particular 
area they were randomly assigned to receive information about; for example, we asked participants about how much they approved "Donald Trump's separation of his personal interests from his officials decisions as a candidate and as President" or his performance in the area related to "The environment." Using data from Survey 1, Table 8 shows results from a regression of Trump's approval in a particular area, on a 1-5 scale, on indicators for each treatment as well as the preregistered pre-treatment covariates and fixed effects for each topic to improve precision. The results show that the specific statements in particular reduced Trump's approval in the area respondents read facts about by a statistically significant -0.14 scale points $(\mathrm{SE}=0.02)$.

In summary, it is not that respondents' views about Trump are not malleable at all; rather, the findings are consistent with voters' overall priors about Trump being sufficiently strong that even changes in perceptions of Trump on particular dimensions are not sufficient to meaningful alter global evaluations of Trump.

These results also cast doubt on the concern that the anti-Trump statements we composed failed to persuade because they were inherently unpersuasive or because respondents were already familiar with the information they contained.

These findings help reinforce our interpretation of why these messages did not appear to meaningfully change evaluations of Trump or vote intentions: it is not that respondents resisted admitting Trump's failings in particular areas, or that our statements failed to communicate these, but rather that respondents had such strong prior beliefs about Trump that their acknowledgment of his failings in one particular area did not meaningfully change their global evaluations of him or their vote choices.

Here, consistent with the role of information in changing even these domain-specific evaluations, we also find that the vague attacks were significantly less effective than the statements providing specific information $(p<0.0001)$. 
Table 8: Effects on Topic Ratings

\begin{tabular}{lc}
\hline & $(1)$ \\
& Trump Approval In Area (1-5) \\
\hline Anti-Trump Specific Statements & $-0.135^{* * *}$ \\
& $(0.021)$ \\
Anti-Trump Vague Statements & $-0.056^{* *}$ \\
& $(0.028)$ \\
\hline Uses Covariates? & $\checkmark$ \\
Topic Fixed Effects? & $\checkmark$ \\
$p$-value: Specific vs. Vague & 0.000 \\
Std. Dev. of DV & 1.47 \\
$N$ & 21,261 \\
$R^{2}$ & 0.625 \\
\hline Standard errors in parentheses & \\
${ }^{*} p<0.10,{ }^{* *} p<0.05,{ }^{* * *} p<0.01$ &
\end{tabular}

\section{Discussion}

When do campaigns successfully persuade voters, and why are their persuasive effects so often minimal (Kalla and Broockman 2018)? Existing findings that campaign effects are smaller in partisan elections and grow smaller over the course of a campaign have two broad potential interpretations. A first is that voters are "intoxicated partisans" who usually resist crossing party lines (e.g., Achen and Bartels 2016, but see Fowler et al. (2020)) and "come home" to vote for their parties as election day draws near and their partisan identities are activated (e.g., Henderson 2015). A second interpretation is informational, and interprets these patterns as reflecting Bayesian reasoning. Under this second view, partisanship is a strong signal about politicians' platform and priorities, providing voters strong prior beliefs about candidates, and therefore leading additional information to have smaller effects in partisan elections. Moreover, as voters gain more information about candidates over the course of an election (Gelman and King 1993; Le Pennec and Pons 2019), the marginal impact of additional information should decline (e.g., DellaVigna and Gentzkow 2010). 
Determining whether "intoxicated partisanship" can completely account for these findings, or whether an informational interpretation also plays a significant role, is significant for understanding both when and why campaigns persuade voters and for understanding voter decision-making more generally. However, it is difficult to isolate diverging predictions of these two explanations in existing studies or from examining variation across elections. To test predictions of these perspectives, we conducted a series of large survey experiments, randomizing tens of thousands of respondents to treatments containing hundreds of different messages about candidates in the 2020 Presidential elections.

Our results were consistent with predictions of an informational interpretation of campaign effects. Our results suggested that there were at most very small persuasive effects on Trump support from either specific or vague attacks on him. Likewise, positive information about Trump also did not appear to meaningfully change Trump's vote margin. This is consistent with voters having strong prior beliefs about Trump-a proposition also consistent with Trump's stable

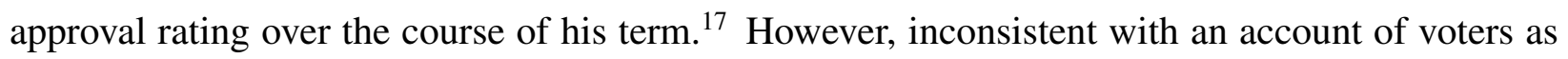
"intoxicated partisans," we found large persuasive effects of showing voters both positive and negative information about Biden, a candidate about whom people have much weaker prior beliefs. This included large effects among Republicans, who were significantly more likely to say they would vote for Biden after shown positive information about him. Further consistent with an informational interpretation, we found that the effects of critical statements containing specific information were significantly larger than vague attacks on him and the other Democratic candidates.

Our work sits within a growing literature emphasizing the importance of information on public opinion. For example, Coppock (2016) shows that survey experimental treatments that provide new information have lasting effects on issue opinions, whereas those that simply remind respondents of existing information have more evanescent effects. Likewise, Leeper and Slothuus (2018) find

\footnotetext{
${ }^{17}$ See https: //projects.fivethirtyeight.com/trump-approval-ratings/
} 
that even the effects of many studies on emphasis framing may in fact be driven by information. Our findings also relate to research finding that low-information voters-i.e., those with weaker prior beliefs_-are especially susceptible to persuasion (Arnold 2012; Fowler and Margolis 2014; Rogers and Nickerson 2013; Zaller 2004).

We hasten to note several limitations of these studies. First, we only examined the effect of information in a single presidential election. Although we tested a number of distinct predictions of the informational and "partisan intoxication" perspectives and utilized hundreds of different treatments, we cannot be certain how results from this election with these candidates would generalize to other settings with different candidates. Donald Trump may have been an unusual incumbent president with a unique ability to dominate news cycles. Second, future work should replicate our findings in field settings (Incerti 2020), especially as election day approaches (Kalla and Broockman 2018) and as candidates respond strategically (Dunning et al. 2019). With this said, demand effects cannot easily account for our findings, as we it is unclear why respondents would resist both pro- and anti-Trump information yet pretend to be persuaded by both pro- and anti-Biden information. Third, our survey data is not well-suited to measure any effects of information on voter turnout (Rogers and Aida 2014), although prior work would suggest any such effects are unlikely (Dunning et al. 2019; Green and Gerber 2019). Finally, although our results are broadly consistent with what would be expected based on Bayesian reasoning, our results are not well-positioned to evaluate whether voters are updating "too quickly" or "too slowly" from the information we provided (e.g., Hill 2017).

In conclusion, although our results surely do not rule out that voters sometimes process information with directional motives, they do challenge a "strong" version of the "intoxicated partisans" thesis, as we find significant evidence of behavior consistent with accuracy motives-behavior which is driven to a great extent by voters crossing party lines. "Partisan intoxication" does not completely explain how voters react to campaigns, but a simple Bayesian interpretation does accord well with many of the patterns we find. In other words, facts do change 
voters minds, and in fact appear to change them especially effectively-but, consistent with Bayesian reasoning, voters who react to new facts do not neglect their prior beliefs when evaluating them.

\section{References}

Achen, Christopher H. and Larry M. Bartels. 2016. Democracy for Realists: Why Elections Do Not Produce Responsive Government. Princeton, NJ: Princeton University Press.

Arias, Eric, Horacio Larreguy, John Marshall and Pablo Querubin. 2018. "Priors rule: When do malfeasance revelations help or hurt incumbent parties?" NBER Working Paper.

Arnold, Jason Ross. 2012. “The electoral consequences of voter ignorance.” Electoral Studies 31(4):796-815.

Banerjee, Abhijit V., Selvan Kumar, Rohini Pande and Felix Su. 2011. "Do Informed Voters Make Better Choices? Experimental Evidence from Urban India.” Working paper.

Belloni, Alexandre, Victor Chernozhukov and Christian Hansen. 2014. "Inference on treatment effects after selection among high-dimensional controls." The Review of Economic Studies 81(2):608-650.

Bloniarz, Adam, Hanzhong Liu, Cun-Hui Zhang, Jasjeet S Sekhon and Bin Yu. 2016. "Lasso adjustments of treatment effect estimates in randomized experiments." Proceedings of the National Academy of Sciences 113(27):7383-7390.

Brady, Henry E., Richard Johnston and John Sides. 2006. Capturing Campaign Effects. University of Michigan Press chapter The Study of Political Campaigns.

Broockman, David and Joshua Kalla. 2020. "Candidate Ideology and Vote Choice in the 2020 US Presidential Election.”. 
Bullock, John G. 2009. "Partisan bias and the Bayesian ideal in the study of public opinion.” The Journal of Politics 71(3):1109-1124.

Campbell, Angus, Philip E. Converse, Warren E. Miller and Donald E. Stokes. 1960. The American Voter. Chicago.

Coppock, Alexander. 2016. "The persistence of survey experimental treatment effects." Available at https: / / alexandercoppock.com/papers/Coppock_persistence.pdf.

Coppock, Alexander and Oliver A McClellan. 2019. "Validating the demographic, political, psychological, and experimental results obtained from a new source of online survey respondents.” Research \& Politics 6(1):2053168018822174.

Coppock, Alexander, Seth J Hill and Lynn Vavreck. 2020. "The small effects of political advertising are small regardless of context, message, sender, or receiver: Evidence from 59 real-time randomized experiments." Science advances 6(36):eabc4046.

DellaVigna, Stefano and Matthew Gentzkow. 2010. "Persuasion: Empirical Evidence.” Annual Review of Economics 2:643-669.

Dimmery, Drew, Eytan Bakshy and Jasjeet Sekhon. 2019. Shrinkage Estimators in Online Experiments. In Proceedings of the 25th ACM SIGKDD International Conference on Knowledge Discovery \& Data Mining. pp. 2914-2922.

Dunning, Thad, Guy Grossman, Macartan Humphreys, Susan D Hyde, Craig McIntosh and Gareth Nellis. 2019. Information, Accountability, and Cumulative Learning: Lessons from Metaketa I. Cambridge University Press.

Fang, Albert H, Andrew M Guess and Macartan Humphreys. 2019. "Can the government deter discrimination? Evidence from a randomized intervention in New York City." The Journal of Politics 81(1):127-141. 
Ferraz, Claudio and Frederico Finan. 2008. "Exposing corrupt politicians: the effects of Brazil's publicly released audits on electoral outcomes." The Quarterly journal of economics 123(2):703-745.

Fowler, Anthony and Michele Margolis. 2014. "The political consequences of uninformed voters." Electoral Studies 34:100-110.

Fowler, Anthony et al. 2020. "Partisan intoxication or policy voting?" Quarterly Journal of Political Science 15(2):141-179.

Gelman, Andrew and Gary King. 1993. "Why are American presidential election campaign polls so variable when votes are so predictable?" British Journal of Political Science 23(04):409-451.

Green, Donald P and Alan S Gerber. 2019. Get out the vote: How to increase voter turnout. Brookings Institution Press.

Green, Donald Philip and Jonathan S Krasno. 1990. "Rebuttal to Jacobson's” New Evidence for Old Arguments"." American Journal of Political Science 34(2):363-372.

Henderson, Michael. 2015. "Finding the way home: The dynamics of partisan support in presidential campaigns." Political Behavior 37(4):889-910.

Hill, Seth J. 2017. "Learning together slowly: Bayesian learning about political facts.” The Journal of Politics 79(4):1403-1418.

Humphreys, Macartan and Jeremy M. Weinstein. 2012. "Policing Politicians: Citizen Empowerment and Political Accountability in Uganda." Working paper.

Incerti, Trevor. 2020. "Corruption information and vote share: A meta-analysis and lessons for experimental design." American Political Science Review 114(3):761-774. 
Jacobson, Gary C. 1990. "The effects of campaign spending in House elections: New evidence for old arguments." American Journal of Political Science pp. 334-362.

Kalla, Joshua L and David E Broockman. 2018. "The minimal persuasive effects of campaign contact in general elections: Evidence from 49 field experiments." American Political Science Review 112(1):148-166.

Le Pennec, Caroline and Vincent Pons. 2019. How Do Campaigns Shape Vote Choice? MultiCountry Evidence from 62 Elections and 56 TV Debates. Technical report National Bureau of Economic Research.

Leeper, Thomas J and Rune Slothuus. 2018. "Can Citizens Be Framed? How Persuasive Information More than Emphasis Framing Changes Political Opinions." Available at https://s3.us-east-2.amazonaws.com/tjl-sharing/assets/ CanCitizensBeFramed.pdf.

McDonald, Jared. 2019. "Avoiding the Hypothetical: Why "Mirror Experiments" are an Essential Part of Survey Research.” International Journal of Public Opinion Research .

Michelitch, Kristin and Stephen Utych. 2018. "Electoral cycle fluctuations in partisanship: Global evidence from eighty-six countries.” The Journal of Politics 80(2):412-427.

Panagopoulos, Costas and Donald P Green. 2008. "Field experiments testing the impact of radio advertisements on electoral competition.” American Journal of Political Science 52(1):156-168.

Rogers, Todd and David W. Nickerson. 2013. "Can Inaccurate Beliefs about Incumbents Be Changed? And Can Reframing Change Votes?” Working Paper RWP13-018, Harvard Kennedy School. URL: http://papers.ssrn.com/sol3/papers.cfm?abstrac t_id=2271654. 
Rogers, Todd and Masahiko Aida. 2014. "Vote self-prediction hardly predicts who will vote, and is (misleadingly) unbiased.” American Politics Research 42(3):503-528.

Wantchekon, Leonard. 2003. "Clientelism and voting behavior: Evidence from a field experiment in Benin." World politics 55(3):399-422.

Zaller, John R. 1992. The Nature and Origins of Mass Opinion. Cambridge University Press.

Zaller, John R. 2004. Floating voters in US presidential elections, 1948-2000. In Studies in public opinion: Attitudes, nonattitudes, measurement error, and change. Princeton University Press. 


\section{Online Appendix}

\section{Contents}

\begin{tabular}{|l|l|}
\hline A Additional Tables and Figures & 33
\end{tabular}

\begin{tabular}{|lll}
\hline O Overview of Data Collection and Relationship with Pre-Analysis Plan & 36
\end{tabular}

\begin{tabular}{ll}
\hline C Statements Used in Studies & 38
\end{tabular}

\begin{tabular}{|lr}
\hline D Pre-Analysis Plan & 38
\end{tabular} 


\section{A Additional Tables and Figures}

Figure A1: Americans Had Stronger Views about Trump than Biden



Notes: Data are from Survey 4. 
Table A1: Regression Results Used In Figure 1

\begin{tabular}{|c|c|c|c|c|}
\hline & \multicolumn{4}{|c|}{ Trump Vote Margin (-1/0/1) } \\
\hline & (1) & (2) & (3) & (4) \\
\hline $\begin{array}{l}\text { Anti-Trump } \\
\text { Specific Statements }\end{array}$ & $\begin{array}{c}-0.014^{* * *} \\
(0.005)\end{array}$ & & & \\
\hline $\begin{array}{l}\text { Pro-Trump } \\
\text { Specific Statements }\end{array}$ & & $\begin{array}{c}0.018 \\
(0.011)\end{array}$ & & \\
\hline $\begin{array}{l}\text { Pro-Democratic } \\
\text { Specific Statements }\end{array}$ & & $\begin{array}{c}-0.036^{* * *} \\
(0.010)\end{array}$ & & \\
\hline Anti-Democratic & & & $0.043^{* * *}$ & $0.064^{* * *}$ \\
\hline Specific Statements & & & $(0.012)$ & $(0.005)$ \\
\hline Uses Covariates? & $\checkmark$ & $\checkmark$ & $\checkmark$ & $\checkmark$ \\
\hline Surveys / Subset & $1,2,3$ & 4 & 1, 2 (Biden Only) & 1, 2 (All Democratic Candidates) \\
\hline$N$ & 49,743 & 10,282 & 6,856 & 34,598 \\
\hline$R^{2}$ & 0.818 & 0.781 & 0.764 & 0.752 \\
\hline
\end{tabular}

Standard errors in parentheses

${ }^{*} p<0.10,{ }^{* *} p<0.05,{ }^{* * *} p<0.01$

Table A2: Regression Results by Study: Effect on Trump Vote Margin

\begin{tabular}{lccccccc}
\hline & $(1)$ & $(2)$ & $(3)$ & $(4)$ & $(5)$ & $(6)$ & $(7)$ \\
\hline Anti-Trump & $-0.016^{* *}$ & -0.017 & -0.010 & & & & \\
& $(0.007)$ & $(0.018)$ & $(0.009)$ & & & & \\
Anti-Democratic & & & & $0.042^{* * *}$ & $0.045^{* *}$ & $0.056^{* * *}$ & $0.090^{* * *}$ \\
& & & & $(0.014)$ & $(0.023)$ & $(0.006)$ & $(0.011)$ \\
\hline Uses Covariates? & $\checkmark$ & $\checkmark$ & $\checkmark$ & $\checkmark$ & $\checkmark$ & $\checkmark$ & $\checkmark$ \\
Surveys / Subset & 1 & 2 & 3 & $1($ Biden) & 2 (Biden) & 1 (All Dems) & 2 (All Dems) \\
$N$ & 32,594 & 2,453 & 14,696 & 4,256 & 2,600 & 21,547 & 13,051 \\
$R^{2}$ & 0.813 & 0.815 & 0.832 & 0.761 & 0.769 & 0.752 & 0.752 \\
\hline
\end{tabular}

Standard errors in parentheses

${ }^{*} p<0.10,{ }^{* *} p<0.05,{ }^{* * *} p<0.01$

Note: Study 4 only contained pro- statements. Results for Study 4 are reported in Table A1. 
Table A3: Regression Results Showing the Effect of Negative Trump Statements by Respondents' Baseline Partisanship

\begin{tabular}{lccc}
\hline & Democrats & Independents & Republicans \\
\hline Anti-Trump & -0.005 & -0.024 & $-0.020^{* *}$ \\
Specific Statements & $(0.007)$ & $(0.017)$ & $(0.009)$ \\
\hline Uses Covariates? & $\checkmark$ & $\checkmark$ & $\checkmark$ \\
$N$ & 22,458 & 8,169 & 19,116 \\
$R^{2}$ & 0.47 & 0.52 & 0.58 \\
\hline
\end{tabular}

Standard errors in parentheses

${ }^{*} p<0.10,{ }^{* *} p<0.05,{ }^{* * *} p<0.01$

Note: The dependent variable in each regression is Trump vote margin (-1/0/1). Partisan leaners are coded as partisans.

Figure A2: Standard Deviation of Specific Anti-Trump Statement-Level Estimates, Observed and Under Sharp Null



Notes: The Figure compares the observed standard deviation of treatment effect estimates of each statement in the anti-Trump experiment to the distribution of standard deviations that would be expected under the null that every treatment had the same effect. 


\section{B Overview of Data Collection and Relationship with Pre-Analysis Plan}

We gathered this data across multiple surveys. As we received data from the first rounds of surveys, we conducted additional surveys to test further implications of our interpretation of the first rounds of surveying. In this section we describe our data collection procedure and how our hypotheses evolved as we collected additional data. Table 3 summarizes the surveys and sample sizes.

We began with Survey 1 in early 2020, a pre-analysis plan for which we filed and is given in Appendix $\mathrm{D}$. In order to test our hypotheses about the role of information in campaign persuasion, we randomly assigned respondents to receive a placebo condition with no anti-Trump content, "specific," or "vague" anti-Trump statements. We hypothesized in our PAP that "specific" statements would be more persuasive. As Survey 1 was in the field, we saw the opportunity to further test our hypotheses by conducting similar tests for the leading Democratic candidates, which we tested by adding a section to the end of Survey 1 randomly assigning respondents to a Democratic candidate and then a placebo condition with no anti-Democratic content, "specific," or "vague" attacks on on the Democratic candidate to which they were randomly assigned.

We had originally planned to conduct analyses on which factors predicted the persuasiveness of the statements (e.g., policy content vs. character content; novel information vs. already-known information). However, as discussed in the paper, the procedure we used identified that there was likely no variation in persuasiveness across the statements except for that produced by sampling variability, leading us to abandon this planned analyses and present these instead. That is, metaanalytic tests of Survey 1's results suggested that anti-Democratic statement were far more effective than anti-Trump statements; and that the anti-Trump statements were likely all similarly effective, consistent with the very small average effects being driven by demand.

To replicate both of these findings, we conducted Survey 2, using only the statements estimated to be most effective in Survey 1. As reported in the paper, Survey 2 found that the 
anti-Trump statements identified as most effective in Survey 1 regressed to the mean, consistent with our interpretation that none of these statements likely has any true effect. However, the Biden statements remained effective. See Table A2 for the full results.

As we discuss in Footnote 16 in the paper, we then conducted Survey 3 to assess an alternative explanation for the findings, that specific and vague statements are complementary and would be most effective when respondents saw once of each. We randomly assigned respondents to a control group, "specific" statements, "vague" statements, or a group that received one statement of each type. With this design, we found no support for this alternative.

Finally, after reaching the tentative conclusion that content about Democrats, including Biden, was more effective than content about Trump, we conduced Survey 4 to assess the alternative explanation that in the 2020 election it is easier to persuade people to vote for Republicans than to vote for Democrats. Were this the case, we would expect pro-Trump statements to be more effective than pro-Biden statements. However, consistent with our interpretation that the results are driven by respondents' weaker prior beliefs about Biden, the evidence from this survey suggested that pro-Biden statements appeared more effective than pro-Trump statements.

Our pre-analysis plan was originally filed with the intention of analyzing the anti-Trump statements in Survey 1. We did not file revised PAPs before the other surveys because we simply follow the same statistical specifications to estimate treatment effect in all the other surveys as in the original PAP.

In the Anti-Trump and Anti-Biden experiments, we composed statements we ex ante categorized as "specific" and "vague," hypothesizing that the "specific" statements would be more persuasive because they contained more information. We randomly assigned respondents to receive either specific or vague statements in Surveys 1 and 2. Survey 3 did the same, but contained a group that received one statement of each type. In Survey 4, we only showed respondents specific statements. 


\section{Statements Used in Studies}

The statements we used in the studies are available at https://osf.io/7n4pz/

\section{Pre-Analysis Plan}

As discussed in Appendix B, we filed the pre-analysis plan below with the intention of analyzing only the anti-Trump survey data. After receiving preliminary results, we conducted further surveying to assess the robustness of our conclusions, and continue using the same statistical analysis plan as in the original PAP. The pre-analysis plan is available at https://osf.io/8x2pr/. 